Revista Iberoamericana, Vol. LXIX, Núm. 204, Julio-Septiembre 2003, 667-688

\title{
AVATARES DEL PROCESO DE LA INSTITUCIONALIZACIÓN DE LA LITERATURA EN CHILE EN LAS REVISTAS LITERARIAS DEL SIGLO XIX ${ }^{1}$
}

\author{
POR \\ J. Agustín Pastén B. \\ University of Nebraska-Lincoln
}

En su estudio sobre José Victorino Lastarria, quien junto a Bello y Sarmiento desempeñó un papel fundamental en la vida intelectual del Chile decimonónico, Bernardo Subercaseaux afirma que su famoso Discurso del 3 de mayo de 1842, entre otras cosas, institucionaliza la literatura chilena (Cultura 62). ${ }^{2}$ Oscar L. Vera, por su parte, al reflexionar sobre la misma en 1933 concluye que ésta sigue siendo "una literatura en formación” (289), mientras que Lautaro Yankas marca el año 1938 como el momento en que recién empieza a tomar forma la literatura chilena (111). El nacimiento de la literatura

\footnotetext{
${ }^{1}$ En la elaboración de este proyecto en curso sobre la institucionalización de la literatura en Chile, que tiene como objeto examinar cuidadosamente el proceso que eventualmente culminará con la autonomización de la esfera literaria en las primeras décadas del siglo xx, han constituido fuentes de inspiración principalmente el estudio de Hohendahl, Building a National Literature, y el de Jusdanis, Belated Modernity and Aesthetic Culture. También han resultado de gran utilidad el clásico texto de Habermas sobre la transformación de la esfera pública (The Structural Transformation of the Public Sphere ) y el de Bürger sobre la vanguardia (Theory of the Avant-garde). The Function of Criticism, de Eagleton, así como Is Literary History Possible? de Perkins y The Meaning of Literature de Reiss, han sido igualmente provechosos. En el marco concreto de la historiografía literaria hispanoamericana en su relación con la modernización desigual que caracteriza a todos los países del continente, los aportes más significativos han sido La historiografía literaria del liberalismo hispanoamericano del siglo xIX, de González Stephan, los estudios de Rama (en especial Rubén Darío y el modernismo y La ciudad letrada), y el texto de Ramos, Desencuentros de la modernidad en América Latina. Finalmente, en cuanto al caso específico del campo literario, cultural y político del Chile del siglo xix, han resultado inmensamente valiosos los estudios de Subercaseaux (en particular Cultura y sociedad liberal en el siglo XIX y Fin de siglo), Stuven, y Ossandón, además de los artículos y libros de Carlos Foresti, Eva Löfquist y Álvaro Foresti y el brillante análisis de Catalán, "Antecedentes sobre la transformación del campo literario en Chile entre 1890 y 1920” (en Brunner y Catalán, 69-175).

${ }^{2}$ La importancia del Discurso de Lastarria ha sido ampliamente señalada por la crítica. "El discurso es un hito en la historia política y cultural chilena," puntualiza el historiador chileno Alfredo JocelynHolt (73). Consúltense las páginas 73-78 de su artículo para un completo análisis del mismo. Este Discurso Inaugural de la Sociedad Literaria en el cual Lastarria pide nada menos que la creación de una literatura nacional, lo publica originalmente el famoso librero español asentado en Valparaíso, Manuel Rivadeneyra. Años más tarde, Lastarria lo incluye en sus Recuerdos literarios (1878). Una versión moderna del Discurso puede encontrarse en Promis Ojeda (80-93).
} 
en Chile, al igual que el nacimiento de cualquier literatura, tiene que verse como un complejísimo proceso mediante el cual, en la medida en que se va construyendo la nación, se va inventando, simultáneamente, una tradición literaria. En un instante en que la producción literaria latinoamericana llena los estantes de las librerías y los certámenes y premios literarios no dejan de sucederse, fácilmente se olvida que no siempre fue así, que hubo que crear la institución literaria y que para que ésta consiguiera autonomizarse hubo primero que cortar el cordón umbilical que la unía a los poderes del Estado. Aunque es indudable que desde los primeros años de su vida independiente Chile gozó de una mayor estabilidad política y social que la mayoría de las demás naciones latinoamericanas en constitución y que antes de su génesis como nación el Estado ya había creado las instituciones estatales correspondientes, ${ }^{3}$ el sinnúmero de revistas literarias publicadas en Chile en el siglo $\mathrm{XIX}^{4}$ revela que la voluntad autonómica de la literatura se estrelló contra la pared en repetidas ocasiones, las más de las veces contra su propio idearium ilustrado, anhelando por una parte la plena modernización de la patria a como diera lugar y por otra exigiendo la fundación de una literatura nacional que se liberara de las pesadas cadenas de la influencia de la literatura europea.

Esta paradoja forma parte de la simultánea búsqueda de lo propio y lo moderno que atraviesa todo el discurso cultural hispanoamericano y que Carlos Alonso denomina "the burden of modernity" ${ }^{\text {y }}$ yo llamaría la "ansiedad” de la modernización. Así como los “parnasos fundacionales” y las “"performances artísticas”” contribuyeron a la "fundación poética del Estado-Nación” (Achugar), y del mismo modo en que las constituciones, gramáticas y manuales de conducta construyeron al ciudadano latinoamericano mediante la eliminación de sus diferencias y la domesticación de sus costumbres (González Stephan "Las disciplinas escriturarias de la patria”), las revistas literarias decimonónicas fueron quizá el principal dispositivo, el escenario, si se quiere, donde la élite dirigente intentó por

\footnotetext{
${ }^{3}$ Para el desarrollo de la noción de estado en Chile, consúltese el clásico texto de Mario Góngora, Ensayo histórico sobre la noción de estado en Chile en los siglos XIx y Xx. Véase, asimismo, el primer volumen de Historia contemporánea de Chile de Gabriel Salazar y Julio Pinto, Estado, legitimidad, ciudadanía, para una perspectiva bastante diferente de la de Góngora.

${ }^{4}$ En la Biblioteca Nacional de Chile tuve la oportunidad de revisar todos los periódicos incluidos en Las revistas literarias chilenas del siglo XIX, de Roberto Vilches. Este pequeño índice contiene una útil descripción de la mayor parte de las revistas literarias publicadas en Chile. Dada la naturaleza de esta clase de periódicos, éstos formarían parte de la "prensa cultural, científica y literaria” del cuadro taxonómico sobre la prensa decimonónica chilena de Ossandón, aun cuando a menudo muestran rasgos de otros tipos de prensa tales como "la prensa política y de barricada," "la prensa doctrinaria," "la prensa comercial e informativa," "la prensa estratega y fundadora” y "la prensa raciocinante e informativa.” Véase el primer capítulo del estudio de Ossandón, "Modos de validación del texto periodístico en el siglo xix: De la 'fundación' al 'raciocinio'” (23-47), para un análisis pormenorizado de cada una de estas categorías. Para una visión global de las nuevas formas discursivas que surgen en América Latina en el siglo xix y las cuales alteran drásticamente la comprensión que se tenía hasta entonces de la vida cotidiana, en particular el significativo papel que jugó la prensa diaria, consúltense el artículo de Roig y también el capítulo "Límites de la autonomía: periodismo y literatura,” del estudio de Ramos (82-111).

${ }^{5}$ En su reciente libro The Burden of Modernity. The Rhetoric of Cultural Discourse in Spanish America.
} 
todos los medios no sólo la “formación de la ciudadanía” (Ramos 93), sino la implantación de una idea, la del progreso, y de una ideología, la de la literatura, como los vehículos más apropiados para la cristalización de la inteligencia y la consecución de la identidad nacional. De todas las artes, la literatura es la que más activamente contribuye a la formación de la nación (Jusdanis 40).

Estudiar el desarrollo de la institucionalización de una literatura implica no tanto escudriñar los textos en sí, su significado, sino más bien, al decir de Barthes, "to amputate literature from the individual” (162), prestar cuidadosa atención no al funcionamiento interno de la obra sino al de la institución (Hohendahl 104), tratando de responder algunos de los siguientes interrogantes respecto del total de la productividad discursiva de un determinado período formativo: ¿qué función se les asigna a la literatura ${ }^{6}$ y a las letras en general en la formación de la nación?; ¿las producciones simbólicas de qué grupos quedan marginadas del circuito letrado?; ¿quiénes son los que escriben y qué labor cumplen en el aparato estatal?; ¿qué porcentaje del total de la población tiene acceso a la educación y quiénes son los que leen?; ¿cuál es el rol de los periódicos en todo este devenir literariopolítico-cultural y cómo se refleja en ellos el prurito por institucionalizar una literatura todavía en pañales? Este estudio centra su atención fundamentalmente en este último interrogante. ${ }^{7}$ En Chile se publicaron aproximadamente unos cincuenta periódicos literarios en el siglo XIX; algunos duraron uno o dos meses, otros varios años. Unos fueron fundados por intelectuales conocidos tales como Alberdi, Sarmiento, y Lastarria; otros por escritores que no dejaron huellas en las letras hispanoamericanas.

Antes de realizar un análisis pormenorizado de los discursos presentes en los periódicos literarios decimonónicos, cabe esbozar primero una definición del término “institucionalización”. Institucionalización se concibe aquí primordialmente como el camino que finalmente conduce a la creación de una institución, en este caso la institución literaria. Pese a que son múltiples los temas que abarca (concepto de literatura, criterios estéticos, etc.), lo fundamental es que se entienda como un proceso, como una búsqueda continua no sólo de la identidad nacional sino también de las pautas y parámetros que adoptarán las letras en general y la literatura en particular en la construcción de la nación.

\footnotetext{
${ }^{6}$ Sobre los cambios que ha experimentado este concepto a través de la historia, véase el apartado "Literature" del libro de Raymond Williams Marxism and Literature (45-54).

${ }^{7}$ Pero también existen otros interrogantes que aunque no reciben una respuesta en este ensayo, habría que responder si se quiere tener una visión completa del proceso de la institucionalización de la literatura en Chile. Por ejemplo, ¿qué se entiende por términos como "literatura," "literario," "bellas letras," "bellas artes," "escritor," "literato,” "periodista,” “escrito”?; ¿ en qué momento empieza a enseñarse la literatura como ramo independiente tanto en el colegio como en la universidad y cuáles son los autores que se leen?; ¿cuáles son los géneros literarios que se privilegian?; ¿en qué instante surgen la industria editorial y el mercado literario?; ¿cuándo y cómo empieza a deslindarse la esfera literaria de la esfera política?; ¿cuáles son los rasgos de una burguesía en ciernes y qué principios de articulación adquiere la opinión pública?; ¿en qué medida la reificación de la vida como consecuencia directa de la modernización afecta la tarea del que Gramsci bautizara como "intelectual tradicional”?; ¿cuál es el carácter de la crítica "literaria” en una época en que no existe aún una clara delimitación entre lo literario como "ficción” y lo literario como "lo intectual” en general?; ¿cuáles son los criterios que emplean las primeras historias de la literatura para aceptar o rechazar un escrito?
} 
A la vez, “institucionalización” viene a constituir el resultado de dicho proceso. ${ }^{8}$ De allí por ejemplo que Ramos, al hablar de la literatura del siglo xix en América Latina (y teniendo muy en cuenta las ideas de Bürger sobre la supuesta “estabilidad” de la institución literaria), se refiera a la “imposibilidad de su institucionalización” (12). Así también Jusdanis, quien escribe: "The institutionalization of literature can be said to have been realized when a certain field of textuality has been isolated and designated literary, a system of norms and conventions established, and a material organization erected" (128). ${ }^{9}$ Es decir, lo que se entiende por la autonomización de la literatura y asimismo el momento en el cual nace la institución literaria al independizarse de las otras instituciones (la política y la cultural, verbigracia). Institucionalización tiene en este ensayo todas las características que Raymond Williams atribuye al concepto “institución” antes de que éste adquiriera su connotación moderna (Keywords 168-69), a saber, un proceso en constante estado de transformación, un procedimiento proteico por excelencia que precede a la creación de todas las instituciones culturales. Así, entonces, cuando Subercaseaux asevera que el Discurso de Lastarria “institucionaliza” la literatura chilena, lo que quiere decir en realidad es que éste pone sobre el tapete su existencia o falta de ella pero no el hecho de que exista ya en 1842 la institución literaria como tal; una cosa es la literatura (con mayúscula o minúscula), otra la institución que la sostiene. A su vez, todas las subinstituciones que contribuyen a la formación de la institución literaria (burguesía, industria editorial, mercado literario, etc.) experimentan sus propios procesos de institucionalización antes de erigirse en instituciones formales. Este artículo centra su atención en un solo componente de la institución literaria (institución que se consolidará recién en la primera mitad del siglo veinte), la prensa "literaria”, en un momento en que el periodismo en Chile no se convierte aún en una institución y cuando las revistas llamadas "literarias" incluyen todo tipo de textos en sus páginas.

Pero antes de pasar a definir las características específicas de este proceso en los periódicos chilenos del siglo xıx, conviene puntualizar, aunque parezca obvio, que a pesar de que los prospectos de las revistas no se cansan de pedir el apoyo de la ciudadanía, el proyecto modernizador mismo se realiza a espaldas del grueso de la población chilena. El discurso iluminista presente en la "prensa cultural, científica y literaria” viene a ser un diálogo a puertas cerradas entre miembros de la clase dirigente en el que, si bien se interpela al pueblo, éste raras veces escucha el mensaje que se le predica pues, en su

\footnotetext{
${ }^{8}$ Entre las definiciones del concepto institucionalización que ofrece un diccionario de sociología, por ejemplo, se encuentra ésta: "the process, as well as the outcome of the process, in which social activities become regularized and routinized as stable, social-structural features” (Jary 325, énfasis mío).

${ }^{9}$ Aunque Jusdanis enfoca su atención en la literatura griega, el quinto capítulo de su estudio, "Spaces of a Public Culture” (122-59), representa un excelente punto de partida para un análisis del proceso de la institucionalizacion de la literatura en general. The Institutions of Art, de Peter Bürger y Christa Bürger, por su parte, constituye un notable análisis sobre las diferentes clases de "institucionalización" del arte que se efectuaron en la sociedad burguesa y preburguesa en Francia y Alemania, en especial el capítulo uno, "The Institution of Art as a Category of the Sociology of Literature" (3-29), y el capítulo tres, "Problems in the Functional Transformation of Art and Literature during the Transition from Feudal to Bourgeois Society" (69-86).
} 
mayoría, se encuentra ocupado trabajando primero en los campos y más tarde en las minas de los mismos señores que no se hartan de reclamar su atención. ${ }^{10} \mathrm{Y}$ si bien es verdad que no toda la intelectualidad decimonónica era dueña de tierras, sí hubo algunos que provenían de la clase dirigente propietaria, como por ejemplo Diego Barros Arana y Benjamín Vicuña Mackenna, dos de los historiadores más influyentes en la formación de la historiografía chilena; ${ }^{11}$ asimismo, todos ellos constituían sujetos de enunciación que hablaban desde el poder y en última instancia abrigaban un concepto aurático de la cultura que no permitía la heterogeneidad ni lo popular. Estos "cruzados y artífices de la “civilización,'” como los llama Subercaseaux (46-47), ${ }^{12}$ eran hombres que pensaban, que habían tenido la oportunidad de recibir una educación formal sólida, que hablaban varias lenguas y que habían viajado a Europa. ${ }^{13}$ Y no sólo eso, sino que en un período formativo en que la esfera literaria no se independizaba aún de la esfera política, los miembros del circuito letrado, incluidos varios escritores, ${ }^{14}$ participaban activamente en la res publica. Por eso resulta absolutamente sorprendente que no se hayan dado cuenta que por muchas revistas que fundaran, por muchos llamados a "esa falange de obreros que ... trabaja por

10 Con excepción de los folletos y periódicos predominantemente políticos que empiezan a publicarse hacia fines del siglo diecinueve y que formarían parte de la "prensa política y de barricada” del cuadro de Ossandón, hay sólo una revista que busca posicionarse de lado de la mayoría y que incluso se identifica con ésta y no con los patricios iluminados: El pueblo (1867), periódico político y literario. En su "Programa” o prospecto (25/Feb./1867), se lee en la primera página: "Las meditaciones del político, las observaciones del sabio han sido siempre revestidas de una capa nebulosa que las oculta a las miradas del pueblo. Popularizar la ciencia en sus variadas manifestaciones políticas, sociales y literarias es una gran misión y un gran fin ... Tal es la misión y el fin a que aspira el PUEBLO" (1). Sobre la situación concreta de ese "pueblo" llamado a embarcarse en la empresa de la civilización, los trabajos que tenía, los sueldos que recibía, su estilo de vida, su cultura, su relación con los dueños de haciendas, el aparato estatal, la fuerza pública y la iglesia, los factores que contribuyeron a su proletarización y el modo en que la "descampesinización” del campo llevó al "bajo pueblo" a invadir las ciudades hacia fines del siglo diecinueve y principios del siglo veinte, consúltese Labradores, peones y proletarios: formación y crisis de la sociedad popular chilena del siglo XIX, de Gabriel Salazar; en este libro el historiador y sociólogo chileno arroja luces sobre la otra cara de la moneda del proyecto modernizador y provee una prueba más de "la pobreza del progreso" propia de los países latinoamericanos. En lo relativo a las consecuencias nefastas que tuvo la idea de "progreso" en el idearium de los patricios criollos de las nuevas naciones latinoamericanas, léase The Poverty of Progress. Latin America in the Nineteenth Century, de E. Bradford Burns.

${ }^{11}$ En su estudio Universidad y nación. Chile en el siglo xIx, capítulo 8, apartado iii (137-48), Sol Serrano ofrece una descripción del perfil social de académicos y profesores, muchos de los cuales colaboraban asiduamente en las revistas literarias en estudio.

${ }^{12}$ En su análisis de la historia del libro en Chile, Historia del libro en Chile (alma y cuerpo).

${ }^{13}$ Así describe Ossandón a estos "sabios” decimonónicos chilenos: "saber enciclopédico, vocación por sentar bases, voluntad realizadora, espíritu sistematizador y proyectual, práctica poligráfica, interés por lo jurídico o lo constitucional, por la educación y la gramática” (24). Para un perfil intelectual más amplio de los patricios iluminados, véanse Burns (35-40) y Rama (La ciudad 25). ${ }^{14}$ En su libro Escritores de Chile siglo XIX, Eduardo Solar Correa destaca la obra de 36 escritores. De éstos, 19 eran parlamentarios, 12 eran ministros o intendentes y 13 eran diplomáticos. Raúl Silva Castro, por su parte, nos informa en su Antología de poetas chilenos del siglo xIX que 18 poetas tuvieron un cargo público importante, 8 fueron parlamentarios, 9 fueron ministros, subsecretarios de alguna cartera o intendentes y 9 se desempeñaron como diplomáticos. 
el mejoramiento social y ansia por darse una literatura propia”, ${ }^{15}$ las condiciones económicas y sociales del país no dejarían que sus sueños se materializaran tan fácilmente. ${ }^{16}$

A lo contrario de otros países latinoamericanos, como por ejemplo México, donde había habido primero una Sor Juana Inés de la Cruz y un Sigüenza y Góngora y más tarde un Bartolomé Hidalgo y un José María Morelos, la herencia cultural de la Colonia en Chile se había caracterizado por una "enseñanza rígida, eclesiástica y proselitista” y una “valoración negativa de la cultura ilustrada y del libro" (Subercaseaux, Historia 2, 8), ${ }^{17}$ lo cual hacía que fuera extremadamente difícil que el credo liberal promulgado por las revistas encarnase en la sociedad civil. La imprenta había llegado a Chile a fines de 1811, pero recién en 1820 empezaron a surgir imprentas particulares y sólo a finales del siglo se comenzó a fabricar papel (Subercaseaux, Historia 29, 31). En general, en la primera mitad del siglo xix la mayoría de los libros eran extranjeros y éstos eran inmensamente caros;

\footnotetext{
${ }^{15}$ En Revista de Sud-América 1 (1860): 1. Como es el caso de muchos de los “prospectos” y artículos que se publicaron en los periódicos decimonónicos, no se incluye aquí el nombre del autor de estas palabras preliminares que llevan el título de "A nuestros lectores.” Revista de Sud-América, una especie de continuación de la Revista del Pacífico (1858), estaba a cargo de recopilar los anales de la Sociedad de Amigos de la Ilustración.

${ }^{16}$ Desde esta óptica, el caso de Francisco Bilbao y su "Sociabilidad chilena" constituye una verdadera excepción. Miembro de la élite dirigente, había sido discípulo de Lastarria y Bello en el Instituto Nacional y conocía a los integrantes de la Generación de 1842, con quienes funda la Sociedad Literaria. En 1850, junto a Santiago Arcos, otro patricio rebelde, crea la Sociedad de la Igualdad. El 10 de junio de 1844, en El crepúsculo - una de las primeras revistas literarias de Chilepublica su ensayo "Sociabilidad chilena," el cual, por las ideas revolucionarias que contenía, causa una fuerte conmoción incluso entre los liberales más progresivos de la sociedad chilena. El yo ensayístico propone en este texto nada menos que un nuevo orden, más democrático, más igualitario, una especie de transformación total de los valores más fundamentales de la sociedad chilena (a la Nietzsche). Sobre todo, condena duramente la fuerte influencia de la iglesia, una de las más conservadoras del mundo hispano, en la polis civil chilena. Asimismo, censura el inmovilismo social y las terribles condiciones en las que se encontraba el trabajador común y corriente en Chile. Como dice Stuven, "Exigir la simultaneidad entre sociedad civil y política será la gran revolución que propone Francisco Bilbao en su 'Sociabilidad Chilena'” (37). Tal fue el escándalo que provocó la publicación de este escrito, que varios ejemplares de El crepúsculo fueron quemados en hoguera pública a la vez que se purgó el ensayo de las copias que no alcanzaron a ver el fuego. La iglesia, a través de su recién fundado órgano, La Revista Católica, publicó una serie de artículos condenando tajantemente las ideas de Bilbao. Lo mismo hizo El Mercurio, periódico conservador por excelencia. Para un análisis sobre Bilbao y su controversial ensayo, léase el capítulo viii del libro de Stuven, "Los límites de la polémica: ‘Sociabilidad chilena’ por Francisco Bilbao” (251-82).

${ }^{17}$ Además de que el número de personas que sabía leer era reducidísimo y que las pocas bibliotecas en el reino de Chile contenían, en su mayor parte, libros de teología en latín, los autores tuvieron que enfrentar extraordinarias dificultades para escribir y publicar sus libros durante la Colonia. Asimismo, el valor del pergamino era inmensamente alto. En contraste con otros países, en Chile fueron escasísimas las sociedades literarias, y los productos escriturales que se produjeron, salvo contados casos, resultaron bastante pobres (Toribio Medina xxx-xxxiii, xliii, xcv-vi). El género que sí practicaron asiduamente los escritores en este "Flandes indiano," como llama a Chile Toribio Medina, fue la "oratoria sagrada" (cxxvii-viii). Sobre la situación de las letras en general en el Chile de esta época, consúltese también Enseñanza de la lectura en Chile (Siglos XVI-XIX), de Ponce.
} 
muchos de ellos, además, provenían de España y su función consistía en promover la doctrina católica. Subercaseaux concluye que pese a que la situación del libro mejora gracias a los esfuerzos de Bello, “entre 1811 y 1840 la producción, circulación y consumo de libros tuvo en Chile un crecimiento lento y escaso" (Historia 40). Pero al reducido tamaño del mercado, a la mala calidad y al alto costo de los libros que sí se publicaban, hay que agregar la no muy favorable situación del sistema educativo y el limitado número de individuos que tenía acceso a la enseñanza. De acuerdo al mismo autor, de un total de 179.000 niños de entre 7 y 15 años, sólo alrededor de 37.000 recibían educación en 1856 (Historia 61). Además, salvo raras excepciones, la mayor parte de la población trabajadora chilena apenas tenía para cubrir sus necesidades más básicas. Su cultura, asimismo, cultura de chinganas, de fondas, de bailes, ${ }^{18}$ se manifestaba en las afueras de la ciudad patricia, mucho más cerca de poetas populares y poesía en pliegos sueltos ${ }^{19}$ que de sociedades literarias y funciones de ópera en el Teatro Municipal. Es seguramente este abismo casi insalvable entre la ciudad letrada y la ciudad real lo que paradójicamente hace que quienes colaboraban en las revistas literarias decimonónicas hayan depositado toda su fe en el poder de la palabra escrita para transformar la sociedad chilena en una sociedad moderna y "civilizada".

Entre 1842 y 1900 se producen en Chile cambios culturales e institucionales que vienen a alterar gradualmente la relación entre la ciudad letrada y la ciudad real. En 1842 se fundan la Universidad de Chile y la Sociedad Literaria. Desde estos nuevos espacios culturales irá surgiendo la disensión y se irán produciendo nutridas polémicas sobre educación y cultura. Se crean la Escuela Normal de Preceptores y numerosas escuelas primarias fiscales. En 1844, Francisco Bilbao provoca un verdadero terremoto en la vida cultural y política chilena con la publicación de "Sociabilidad chilena”, ensayo en el que exige no sólo derechos civiles para los estratos bajos y medios sino también la total separación entre la Iglesia y el Estado. La opinión pública empieza a imponerse poco a poco y con ella aparecen los primeros rasgos de una burguesía incipiente. En el plano político, el autoritarismo que había caracterizado la década de 1830 comienza a ceder al parlamentarismo, produciéndose así la paulatina aparición de partidos políticos. Los acontecimientos revolucionarios que ocurren en Francia en 1848 tienen una amplia repercusión en la clase política chilena. La doctrina socialista comienza a difundirse gradualmente y se fundan la Sociedad Demócrata, el Club de la Reforma y la Sociedad de

\footnotetext{
${ }^{18}$ Salazar provee un resumen de las diferentes actividades culturales que desarrollaron labradores, peones y proletarios y que, con el tiempo, fueron siendo apropiadas por la clase patricia en la misma medida en que ésta se daba cuenta que podía sacar provecho económico de la administración de chinganas y cañadas (Labradores 119-26). Al éxito social, cultural y hasta económico de estas actividades para los administradores campesinos, sucedió primero la represión policial de casi "todas las formas públicas de diversión campesina” y, más adelante, la institucionalización tributaria de las chinganas (Salazar, Labradores 120, 126).

${ }^{19}$ Concebir la "poesía popular de pliegos sueltos" y los folletos que circulaban en el siglo diecinueve en Chile como "periodismo popular" como lo hace Gina Canepa, me parece bastante acertado. Según esta estudiosa, la poesía popular de pliegos sueltos constituye la "primera vez que en la historia del país se articula un discurso popular tan coherentemente, sin la intervención del grupo letrado o de empresas comerciales” (152).
} 
la Igualdad (1850). Esta última ambicionaba nada menos que "incorporar al pueblo a la política contingente” (Foresti, Carlos, La narrativa, Tomo I, 60), proveyendo de educación a los trabajadores y en especial a los artesanos. Pese a estos intentos, empero, no se produce realmente la integración social de la nación; a lo largo del siglo predominan las políticas privadas y la filantropía por sobre las políticas públicas de unidad e integración. En lo económico, Chile se incorpora progresivamente a la economía mundial, generándose inicialmente una casi exclusiva dependencia con Inglaterra en detrimento de la empresarialidad productiva local. Con el tiempo, el refinamiento desplaza a la sencillez entre los miembros de la élite chilena. Culturalmente, hay un gran interés por el teatro, la ópera y las artes, y en 1849 se inaugura una escuela de pintura. En la década de 1850, el francés y el latín son los idiomas extranjeros más estudiados. Martín Rivas aparece en 1862 y ofrece una visión inmensamente realista de la sociedad chilena de la época. A medida que avanza el siglo, persiste el patriotismo ilustrado pero sin que se opere un acercamiento real entre la clase dirigente y la mayor parte de la población; la burguesía sigue siendo todavía un grupo relativamente pequeño. En las últimas décadas del siglo xıx, en la medida en que los campesinos abandonan el campo y los mineros dejan las minas, se lleva a cabo un intenso proceso de urbanización que se traduce en el nacimiento de la prensa popular y en la lenta proletarización industrial del “peonaje” (Salazar, Estado 147). Aun cuando a partir de 1880, y especialmente una vez terminada la Guerra del Pacífico (1879-1883), Chile experimenta un rápido proceso de modernización en el área económica, políticoadministrativa y social, en la ciudad real se multiplican los barrios obreros y conventillos y aumentan las asociaciones populares. También es cierto, en cualquier caso, que mientras la aristocracia urbana construye mansiones en el mejor estilo europeo y asiste al Club Hípico y a la ópera, se producen transformaciones en la ciudad real que van a ir mejorando paulatinamente la vida cultural y social de fines del siglo xIx. Por ejemplo la fundación de la Universidad Católica (1888), la creación del Instituto Pedagógico (1889) y el Consejo de Higiene (1892), la libertad electoral y la libertad de cultos, entre otros. La llegada de Rubén Darío en 1888, por otro lado, contribuye a que la literatura, y particularmente la poesía, empiece a independizarse poco a poco de su papel de constructor de la nación. Aparece en el escenario cultural chileno un nuevo artista, libre ya de la política y el Estado. En resumidas cuentas, es evidente que entre la década de 1840 y la de 1890 se hace más angosta la brecha que separa a letrados y no-letrados en gran parte merced a las instituciones culturales y político-sociales que se establecen en Chile. No sorprende por eso que a pesar de que en 1895 existe todavía un 68.2 \% de población analfabeta, el número de periódicos de toda laya que se publica sigue creciendo a pasos agigantados. ${ }^{20}$

Aun cuando el camino que lleva a la prensa chilena a transformarse de un órgano de ilustración en un órgano de información es largo y penoso, y pese a que el antagonismo entre el campo literario y artístico y la burguesía -antagonismo que Bourdieu juzga clave para la autonomización del arte (58-59)- comienza a fraguarse en Chile recién a fines del siglo xIx, todas las revistas literarias, desde la Revista de Valparaíso (1842) hasta La Revista Nueva (1900), construyen un andamiaje conceptual que refleja claramente la

\footnotetext{
${ }^{20}$ La información de este párrafo proviene fundamentalmente de mis lecturas de los estudios de Foresti (Tomo I), Salazar (Historia ), Stuven, Subercaseaux y Sergio Villalobos R.
} 
visión profundamente optimista que tenían de sí mismos y del país los patricios iluministas. Dicho andamiaje sienta sus bases sobre lo que Wittgenstein denominaría "family resemblances”, generándose particularmente en los prospectos de los periódicos pero así también en artículos dedicados específicamente a asuntos literarios, grupos de términos e ideas que en su mayoría no cumplen otro propósito que el de alentar la elaboración de un proyecto modernizador que estuviera anclado en el intelecto y el amor patriae. De este modo, a conceptos tales como "vicios," "hábitos perniciosos," el "pueblo" y "sus malas tendencias,” “oscuridad” y otros, se opone un gran caudal de voces que podría agruparse de la siguiente manera: a) Nociones que guardan estrecha relación con la idea de convertir a Chile en una nación culta y "civilizada”: "civilizar [al] pueblo,” "ilustración,” "las semillas de la inteligencia,” “cruzada,” “desarrollo intelectual del país,” “virtud”; b) Términos que tienen que ver con las metas sociales que se proponen quienes colaboran en las revistas: "el bien sagrado de la patria," "los fines sociales," el "mejoramiento de todas las clases sin escepción,” “un periódico de utilidad general,” “provechosa al pueblo,” "la marcha social," "servicio,” “servir”; c) Voces en las que la visión inmensamente positiva que se tiene de Chile se funde con un patriotismo a veces desenfrenado: "la prosperidad de la patria," "las glorias de nuestra patria," "la población civilizada del país," "los progresos visibles de nuestra patria,” "el progreso nacional;” d) Vocablos relacionados directamente con la modernización del país y de los cuales la palabra "progreso" constituye sin duda el master trope ${ }^{21}$ por excelencia; de todos los vocablos presentes en la revistas literarias, éste es el más ubicuo y el que de una u otra forma comprende a todos los demás: “los avances científicos,” “ciencias,” “desarrollo,” “adelantos.” Se trataba no sólo de "crear ... la sociabilidad” apropiada sino también de "corregir” la sociabilidad imperante mediante la educación formal del pueblo (Poblete, "Lectura” 11, 13).

Ahora bien, ¿qué instrumento más apropiado que la prensa ${ }^{22}$ para encarnar el progreso? Basta fijarse en los títulos de algunas de las revistas -El crepúsculo (1843 y 1878), La juventud (1867), La linterna (1867), El alba (1871), La esperanza (1871), La estrella del progreso (1876), Revista del progreso (1888)-así como en el inmenso número de publicaciones periódicas de toda clase que se publicaron en Chile durante el siglo xIX, para darse cuenta de la fe casi desmedida que tenían en el poder transformador de la prensa los patricios modernizadores. ${ }^{23}$

\footnotetext{
${ }^{21}$ De la misma forma que, de acuerdo a Alonso, podría arguirse que la modernidad constituye "the master trope of Western hegemonic authority" (19-20).

${ }^{22}$ Fuera del término "prensa," las revistas literarias emplean las palabras “periódicos” y "prensa diaria" para referirse al mismo tipo de órgano informativo. En algunos casos se utiliza incluso el vocablo "diarismo" y, hacia fines de siglo, el concepto "diario" adquiere carta de ciudadanía. Muchos de los medios literarios decimonónicos, sin embargo - como, por ejemplo, El museo de ambas Américas (1842), la Revista de Santiago (1848), la Revista del Pacífico (1858), entre otrosacaso con el propósito de posicionarse favorablemente en la esfera pública y al mismo tiempo aumentar el número de sus suscriptores, busca separarse de la "prensa diaria" y el "diarismo" arguyendo que éstos, por estar preocupados por las “cuestiones del día,” no están en condiciones de profundizar en temas de interés público.

${ }^{23}$ Con la misma fe, el mismo optimismo, había sido recibida en Chile la llegada de la imprenta. En uno de los artículos que publicara Fray Camilo Henríquez, el director del primer periódico que
} 
Hoi que la lucha contra los opresores está ya terminada, al ruido de las armas debe seguir el ruido de la prensa, poderosa palanca que todo lo reforma y que, como un nuevo sol inventado por el hombre, lleva do quier a la luz de la civilización, presta vida al espíritu y esparce i eterniza las flores de la intelijencia. (“Nuestras ideas” 2)

La prensa se concibe así como el instrumento más apto para “civilizar” el país. ${ }^{24}$ Los dueños y editores de La revista de Chile (1898) no dejan dudas al respecto cuando señalan la meta de su revista: “contribuir al progreso de la sociedad en la que va a circular” (Arrieta C. et al. 1). Al mismo tiempo, empero, la prensa serviría el propósito de reflejar "nuestras glorias, nuestros progresos y adelantos en todo jénero" ("El correo" 73). Por una parte, entonces, la prensa como vehículo, como medio; por otra, ésta como espejo, como reflejo de una convicción. La intelectualidad crítica chilena no tiene la menor duda de que Chile es "la más adelantada indudablemente de todas las repúblicas sudamericanas" "Verdades amargas” 97). Este optimismo se percibe en todas las revistas literarias y políticas de la época. ${ }^{25}$

Una nación moderna y “adelantada” -o al menos significada así mediante el discurso y quizá únicamente en relación a Santiago, Valparaíso, Concepción y La Serena ${ }^{26}$ - no podía, lógicamente, prescindir de un órgano que la representara. Esa era, indefectiblemente, la más valiosa de sus funciones. Sin embargo, los fundadores y colaboradores de revistas estaban muy conscientes de que no bastaba con el progreso material de Chile, que los avances materiales y científicos que se producían debían ir acompañados de adelantos en el campo literario e intelectual. Una nación rica económica y socialmente no debía sino dar origen a una literatura igualmente rica (Hohendahl 211). La elaboración de sus mecanismos venía a constituir un paso más hacia el advenimiento de la muy ansiada modernización (Jusdanis 75). Quien más adecuadamente expresa este sentimiento es

apareció en el país (la Aurora de Chile ), se lee: "Está ya en nuestro poder el grande, el precioso instrumento de la ilustración universal”. "Con su luz hará feliz a los pueblos y ahuyentará los sueños y las sombras,” rezaba el lema en latín que sirvió de epígrafe a este periódico (en Subercaseaux, Historia 20).

${ }^{24}$ La esperanza era que la prensa llegara hasta los lugares más recónditos de la sociedad civil chilena: "Pero de lo que el editor de La lectura debe estar persuadido es de que sus hojas, ... penetrarán como otros tantos rayos de luz en el domicilio de las clases medias, en el taller del obrero, en el fondo mismo de la tenebrosa mina en que el operario del progreso y del engrandecimiento de Chile mora y trabaja" (Vicuña Mackenna 2).

${ }^{25}$ En la sección "Bibliografía” del periódico Biblioteca republicana (1894), por ejemplo, José Bernardo Suárez escribe: "En historia nacional y literaria, Chile es una de las naciones más adelantadas de la América del Sur" (20-21).

${ }^{26}$ A lo largo de todo el siglo xix, se escucha en los periódicos literarios múltiples llamados a “civilizar” y "pacificar” el campo chileno y a difundir la educación en los sectores rurales del país. Aunque no de modo tan insistente ni elaborado como en las obras de Sarmiento, la dicotomía civilización/barbarie es el motor que impulsa el pensamiento intelectual de la época. Los patricios modernizadores están conscientes de que fuera de Santiago, Valparaíso y una que otra ciudad, el "progreso" no ha llegado todavía al resto del país. Y no resulta accidental, por lo mismo, que estos llamados a la educación de las masas y a la pacificación de los indios coincidan con el sinnúmero de artículos consagrados a resaltar la urgencia de poblar el sur de Chile con inmigrantes alemanes. 
Rosario Orrego de Uribe, directora y fundadora de la segunda etapa de la Revista de Valparaíso (1873) y una de las pocas mujeres intelectuales de la época. ${ }^{27}$ Asevera ella en el "Prospecto":

Al fundar la Revista de Valparaiso nos alienta la esperanza de que encontrará en el público la protección que se debe a un periódico llamado a ser el reflejo de una sociedad distinguida como la nuestra ... Valparaiso ha llegado por su progreso material a ser uno de los puertos más hermosos y ricos del Pacífico, y debe esforzarse para llegar a ser uno de los pueblos más cultos e ilustrados. (3)

"Reflejar” y a un tiempo “promover” el progreso material e intelectual de la nación, he ahí la doble misión de los medios literarios. La Revista del Pacífico (1858), por ejemplo, se presenta a sí misma como el "complemento de los progresos visibles de nuestra patria” ("Prospecto” v), mientras que la Revista de Santiago (1872) procura eregirse en el "reflejo de los progresos intelectuales del país” (“Nuestros propósitos” 1).

Dejar constancia de los adelantos que se iban produciendo en la nación y paralelamente coadyuvar en su ejecución, formaba parte de la "cruzada de la inteligencia" en la que se embarcaron los periódicos literarios decimonónicos. ${ }^{28}$ "Rogámosles [a todos los hombres ilustrados y amantes de la América] que vengan a alistarse en esta cruzada para emprender la conquista pacífica y benéfica del espíritu sobre la ignorancia” ("Prospecto,” El museo de ambas Américas 10). Había que sacar a Chile y a América de las tinieblas en las que las había dejado la Colonia. De ahí que la repetición de términos tales como "intelijencia," “ilustración” y “civilizar” cobre tanta importancia en el discurso iluminista de la época.

\footnotetext{
${ }^{27}$ La casi inexistente presencia de la mujer en la vida intelectual del Chile decimonónico explica los diversos llamados que se le hacían a los miembros del "bello sexo" a que contribuyeran con sus poemas y escritos a los periódicos literarios (“Prospecto," El alba 3 y "Prospecto,” El crepúsculo [1878] iv, verbigracia). Desde muy temprano, existe la conciencia de que debe incorporarse a la mujer a la vida cultural e intelectual de la nación, puesto que “... [ese sexo delicado] ya no quiere, ni debe, ser excluido del banquete de la intelijencia” (“Prospecto,” El museo de ambas Américas 10). En 1843, en la "Sociedad literaria" de Santiago, se presenta el ensayo "Influjo del bello sexo sobre la suerte de la humanidad y necesidad de su buena educación” (“Influjo”); y en El crepúsculo (18431844), el mismo periódico que publicara el revolucionario ensayo de Bilbao, se publica "Observaciones sobre la educación de las mujeres dirijidas a las señoras directoras de colejio en Santiago” (J. N. E. 407-19), donde se lee: "Nada es tal vez más perjudicial a una nación que comienza una existencia nueva que el absoluto abandono de la educación de las mujeres” (407). La misma Rosario Orrego de Uribe lee en la Academia de Bellas Letras de Valparaíso su poema "La mujer": "Instruid a la mujer, si quereis pueblos / que se eleven felices, soberanos. / Mirad que la mujer tiene en sus manos / la vasta cuna del humano ser” (Orrego de Uribe, “La mujer” 90). Finalmente, Euridice Pinochet, presidenta de la Academia Literaria de un colegio de mujeres, exhorta a sus compañeras a "cultivar [la] intelijencia," ya que la meta del estudio de las letras no ha de ser otra que "el perfeccionamiento de la mujer" (13). En lo tocante al valioso papel que jugaron Alberto Blest Gana y la novela nacional en la incorporación de la mujer y los sectores medios a la historia chilena, léase el excelente artículo de Poblete, "La construcción social de la lectura y la novela nacional: el caso chileno".

${ }^{28}$ La sólida Revista de Santiago (1855) anhela convertirse incluso en nada menos que la “representante de la intelijencia” (Matta 46).
} 
En la mayoría de los casos, la tarea civilizadora se concebía como una batalla urgente que tenía que librarse lo más expeditamente posible.

Del mismo modo que en el campo de batalla nunca está demás un nuevo soldado, otro brazo y otra espada, así también en el terreno de los debates de la intelijencia, no pueden perjudicar un nuevo campeón, otro combatiente, otro defensor de las luces y de la verdad. (“Nuestros propósitos”, La esperanza 1)

Pero para que las “semillas de la intelijencia” (Orrego de Uribe 3) cayeran en tierra fértil, algunos pensaban que los periódicos debían ser más baratos ("Civilización de las provincias” 101). Con frecuencia, además, y aun cuando hacia fines de siglo se hacen sentir voces que condenan la mercantilización de la vida urbana chilena, los editores de revistas literarias subrayan la importancia del comercio para el bienestar del país; ${ }^{29}$ no sorprende así la paulatina aparición de avisos en algunas de estas revistas. ${ }^{30}$

En última instancia, se anhelaba transformar a Chile en un país moderno por todos los medios disponibles. Pero, como se dijo arriba, no era suficiente con que se poblara el campo con máquinas nuevas ni Santiago ni Valparaiso con los últimos artículos de lujo traídos directamente de Europa; lo fundamental era transformar el corazón de la sociedad chilena. De la misma manera en que la prensa literaria busca divulgar y manifestar el progreso, entonces, también intenta ser útil al público lector. Por eso que fuera de poemas, novelas, obras de teatro y artículos de crítica literaria, aparecen en sus páginas un sinfín de artículos dedicados a la economía, la agricultura, la medicina, el comercio, las leyes. ${ }^{31}$ Al mismo tiempo, puesto que el teatro se pensaba como uno de los vehículos más útiles para ilustrar a la población (un tipo de “"escuela de costumbres”” al decir de Dunia Galindo

\footnotetext{
${ }^{29}$ De acuerdo a los editores de la Revista del progreso (1888), los esfuerzos de la inteligencia no podían prescindir de los adelantos del comercio ("Nuestra primera palabra” 2).

${ }^{30}$ Como había de esperarse, con el gradual proceso de la división del trabajo en el mundo de las letras, y en la medida en que la literatura comienza a autonomizarse de los demás saberes, va aumentando la publicación de avisos en los órganos literarios. Pero los productos que empiezan a llenar sus páginas no siempre son bienes de lujo tales como vestidos recién llegados de París, o bien artículos más prácticos como la última y más moderna máquina para recoger el trigo, sino también noticias de nuevas publicaciones. Esta modalidad aparece por vez primera en El correo literario (1867). Al final del número dos de este periódico, se publica una hoja llena de avisos (32) la cual se titula precisamente "Avisos" y en la que se promociona una serie de revistas ("El Charivari. Periódico crítico, político, literario”, "La Reforma. Periódico político-literario”, entre otras) con la más mínima información editorial: precios de suscripción, tipo de encuadernación, lugares de venta, etc. Para un caso análogo aunque posterior en el contexto periodístico latinoamericano en el que no sólo avisos sino también dibujos, caricaturas y fotografías empiezan a poblar las páginas de las revistas, consúltese el artículo de Eduardo Romano sobre el semanario argentino Caras y Caretas.

${ }^{31}$ Muchos de estos artículos eran sacados directamente de revistas europeas e insertados en las revistas nacionales después de haber sido traducidos. Otros eran escritos por intelectuales chilenos o por extranjeros asentados en Chile. He aquí algunos de los artículos entre cientos que se publicaron a lo largo del siglo: "Teoría de un sistema administrativo y económico para la República de Chile", “Crónica comercial”, “Situación económica del país”, “Estadística de la flora chilena”, "El principio para trazar la línea fronteriza de la Cordillera de los Andes entre Chile y Argentina”, etc.
} 
[36]), ${ }^{32}$ son asaz abundantes las referencias y crónicas consagradas a él. ${ }^{33}$ El discurso mismo mediante el cual se elabora la idea de servicio y utilidad, empero, resulta bastante vago en general, aunque no siempre. La Revista de Santiago (1848), por ejemplo, habla de cumplir los “fines sociales" sin definir cuáles son éstos ("Prospecto" 6).$^{34}$ Otros medios literarios simplemente no distinguen entre los utile y lo dulce, atribuyendo a la cultura poderes que ésta no tenía. Existía la creencia que mientras más se difundían "los elementos de la cultura” en el pueblo, mayor sería la transformación positiva de éste. ${ }^{35}$ Por otro lado, están la Revista de ciencias y letras (1857), la que persigue la utilidad por medio de la publicación de los últimos avances científicos que se vayan produciendo, y La linterna (1867), cuyos artículos "tratarán de reformas sociales que convengan a nuestro adelanto, al mejoramiento de todas las clases sin escepción, pero deteniéndonos principalmente en la clase del pueblo, en la clase obrera" ("Prospecto" 2).

Sea como fuere, ya discurso difuso sobre el concepto de lo social y lo útil, ya elaboración de reformas sociales puntuales, el caso es que los patricios modernizadores se sentían extraordinariamente patrióticos. Vocablos tales como "nacional”, "espíritu nacional”, "patriótico” y "patria” resultan incluso tan prevalentes como "modernizar”, “civilizar” y "progresar” en el discurso literario decimonónico, especialmente en la década de 1840. Sin lugar a dudas, el espacio periodístico buscaba cumplir la misma función que cumpliría el espacio pedagógico especialmente entre 1895 y 1925 en Chile: a un tiempo producir y reproducir las subjetividades nacionales (Poblete, "El Castellano" 22). Los redactores de El semanario de Santiago, verbigracia, hacen hincapié en el hecho de que, no obstante "la conquista de Europa" entre los jóvenes, ellos (los redactores) son chilenos y no ansían sino “el bien sagrado de la patria” ("Prospecto” 1). Ese mismo año (1842), Lastarria exhorta a sus compañeros a sacrificarse "por la utilidad de la patria” (7).

\footnotetext{
${ }^{32} \mathrm{O}$ el teatro como "plataforma pedagógica” que Galindo prefiere leer como "un programa de control y vigilancia asociado a los propósitos hegemónicos de ciertos sectores de poder representantes de la avanzada liberal” (36).

${ }^{33}$ Desde un principio (en 1842, en El semanario de Santiago ) las revistas literarias incluyeron en sus múltiples y variopintas secciones semanales -el "Correo semanal," "Crónicas," "Revista semanal," "Historia de la semana," "Ecos de la semana," "Semana teatral," etc.- secciones de crítica teatral donde se analizaban minuciosamente las obras de teatro que se presentaban en Santiago. Aparte del análisis de las obras mismas, se criticaba con bastante frecuencia la apatía del público, un público que de acuerdo a los críticos esperaba que se presentaran obras nuevas todas las semanas sin darse cuenta de lo caro que les resultaba a los empresarios teatrales el montaje de las mismas. De los periódicos literarios de la época, El mosaico (1846) es el órgano que más sistemáticamente examina el teatro como fenómeno socio-cultural, entrando en abierto debate con críticos teatrales de otras revistas -por ejemplo con el autor de la sección "Estudios teatrales” de El progreso- a la vez que dedicando artículos a los aspectos puramente económicos del arte dramático -verbigracia, "El teatro considerado como especulación mercantil" ("El teatro" 5-7).

${ }^{34}$ El semanario de Santiago (1842), por el contrario, aunque habla de "propender al bien jeneral" ("Prospecto" 1) y "mejorar los aspectos sociales de la sociedad" (194), al menos ofrece ejemplos concretos de su meta: "Hemos recomendado la fundación de un montepio civil que proporcione subsistencia a las familias de los empleados difuntos, y... "("Política” 194).

${ }^{35}$ Esta frase proviene de un artículo sin nombre que se encuentra en el primer número (Tomo 1) de la revista La estrella del sur (1851): 2-3.
} 
Paradójicamente, empero, parece que mientras con más ahinco se aspiraba a la modernización y europeización del país, ${ }^{36}$ más frecuentes eran los llamados a la búsqueda del espíritu nacional y mayormente tangibles se hacían los obscáculos en la cristalización de la empresa ilustrada. Los múltiples llamados al patriotismo presentes en los periódicos literarios guardan una estrecha relación con la percepción de cierto sector del grupo hegemónico de que existían problemas prácticos en la ciudad real que la ciudad ideal no estaba en condiciones de resolver, por más revistas que se fundaran y por mucha tecnología que se importara.

La otra cara del optimismo de una prensa literaria que constantemente convocaba al progreso, al patriotismo, a la civilización y a los objetivos sociales, está marcada por frecuentes quejas, pedidos de auxilio y hasta cierta desesperación de parte de la intelectualidad crítica. El pesimismo que la embargaba podría resumirse en los siguientes apartados: a) La naturaleza efímera de los órganos literarios; b) El escaso interés por el estudio de parte de la mayoría; c) Los escritores como pobres muertos de hambre; d) La poca originalidad de la literatura chilena y; e) La condena del lujo y el materialismo, especialmente en los últimos lustros del siglo XIX.

De todas estas preocupaciones, indudablemente la que adquiere un carácter de urgencia en el proceso de la institucionalización de la literatura en Chile es la que dice relación con la corta duración de la mayor parte de las revistas literarias decimonónicas. Quienes fundan este tipo de órganos, ya sea intelectuales de peso como Bello y Barros Arana, o jóvenes que recién se iniciaban en el camino de las letras, como por ejemplo los estudiantes que fundan La juventud (1867) y La esperanza (1871), están conscientes de que, por una serie de razones históricas y culturales que a veces ellos sencillamente rehúsan aceptar, es bastante complicado mantener a flote los periódicos literarios. Algunos hablan del problema de la suscripción, "la tisis de los periódicos” (Matta 46), a la vez que de "la glacial indiferencia" ${ }^{37}$ con que generalmente se reciben las nuevas publicaciones en Chile (“Prospecto,” El alba 2). Otros, más realistas quizá y conscientes del aspecto mercantil de la revistas, aluden al alto precio de las mismas ("Prospecto,” $\mathrm{La}$ estrella del progreso 1) y al hecho de que éstas padecen, paradójicamente, de "la protección raquítica e intermitente” de parte del Estado (Vicuña Mackenna 2). En la mayoría de los casos, no obstante, aunque se pone énfasis en la condición perecedera de las revistas, no se aducen causas específicas (F.L.B. 32; "Prospecto,” El correo literario [1867] 1).

\footnotetext{
${ }^{36}$ Después de todo, existía la firme creencia de que "La América civilizada no es otra cosa que la Europa establecida en este continente” (González 304). Por otro lado, también es verdad que mucho antes que Martí, Rodó y el Darío de Cantos de vida y esperanza, cierto sector de la intelectualidad chilena ya había lanzado gritos de alarma contra la servil imitación de Europa y Estados Unidos de parte de algunos miembros de la clase dirigente, al igual que de escritores que imitaban modelos literarios europeos sin ningún espíritu crítico. Por ejemplo en los libros La América (1865) de Lastarria y La América en peligro (1862) y Evangelio americano (1864) de Bilbao, así como en el Discurso de incorporación a la Facultad de Humanidades de la Universidad de Chile de Alberto Blest Gana.

${ }^{37}$ Los editores de la Revista de artes y letras (1884) lamentan que tantas publicaciones en Chile hayan "tenido que sucumbir yá por falta de recursos, ya las más veces, bajo el peso de la indiferencia pública” (“Advertensia” 3).
} 
A pesar de ello, y teniendo en cuenta la infinidad de llamados a la juventud así como las múltiples referencias al precario estado de la educación en Chile, resulta innegable que para la élite dirigente una de las principales causas de que los medios literarios careciesen del amplio apoyo del público guardaba estrecha relación con la apatía generalizada por todo lo que tuviera que ver con el intelecto y especialmente por la lectura incluso entre quienes sí disponían de los medios económicos.

El pueblo de Chile habla poco, lee menos, ... Son poquísimos, tomando el tanto por ciento
de la población, los que leen, e infinitamente menor es el número de los que hacen por
leer diverso sacrificio que el de sus ojos y el de una vela ... De aquí es que con dos o tres
escepciones (tal vez una va de más) todos los grandes diarios languidecen y todas las
revistas científicas y literarias siguen la suerte de los párvulos en este sano clima, es decir,
mueren en la lactancia ... Las compañías de seguros urbanos aseguran en Santiago
muebles, alacenas, sofás, ollas de cocina, pero no aseguran libros porque o no los hay o
no vale la pena de preguntar por ellos. (Vicuña Mackenna 1)

Las críticas contra la indiferencia del público por la lectura son abundantes aun cuando en la segunda mitad del siglo, en la medida en que evolucionaba el mercado editorial y aumentaban los sectores medios, se libraba en Chile una encarnizada lucha por la apropiación de la subjetividad del sujeto lector, y especialmente lectoras, a través de la novela nacional de costumbres (Poblete, "La construcción”). ${ }^{38}$ Nadie lee en Chile y escasean las lecturas “populares,” se decía (“Civilización de las provincias” 100). En un país donde no es necesario "saber leer ni escribir para ser ministro o presidente,” la crítica resulta casi inexistente y es mínimo el aprecio por el escritor y lo intelectual (F. M. 143; Blest Gana, Joaquín 68). El chileno vive sólo “para comer, para los placeres materiales”; le tienen sin absoluto cuidado los autores de la hora (Blanco Cuartín 9, 5). Tampoco le interesa demasiado la cultura (“Algo sobre el teatro" 124-25). En general, los "productos de la intelijencia” se reciben con total impasibilidad (L. J. C. 4). Luis Orrego Luco, un novelista de fines de siglo, expresa mejor que nadie no únicamente la gran distancia que existía entre la ciudad letrada y la ciudad real sino también el aislamiento que afectaba hasta los mismos escritores: "A medida que avanzo en la vida me voy convenciendo de la esterilidad de la crítica en un país donde hay pocos escritores, estrechamente relacionados entre sí y aislados de una sociedad que bien poco se preocupa de ellos” (34).

La esfera propiamente literaria no se había constituido como tal todavía; estaba en vías de establecerse ${ }^{39}$ El escritor no estaba aún en condiciones de vivir de lo que producía y la crítica literaria, pese a uno que otro intento aislado, no se había eregido en la institución que llegaría a ser más tarde. En suma, faltaba algún tiempo para que la división del trabajo irrumpiera en la esfera literaria. Por eso que no asombran las continuas alusiones al estado miserable en el que tenían que vivir los escritores. Ni siquiera Jotabeche, uno de los autores costumbristas de mayor renombre, se salvaba; a pesar del cuantioso número de artículos

\footnotetext{
${ }^{38}$ El intelectual Francisco A. Pinto resume las críticas del momento en su artículo "Consecuencias del indiferentismo literario."

${ }^{39}$ Como lo han visto Catalán, Subercaseaux y Ossandón en el caso particular del campo literario chileno, y Gutiérrez Girardot, Rama y Ramos en el marco general del modernismo latinoamericano.
} 
que había publicado, seguía siendo pobre e inclusive se le hacía difícil hallar trabajo en Santiago (“Al lector” 5). Al final del número 24 de la revista El museo (1853), se incluye un poema en prosa ("Muerte de la poesía”) asaz ilustrativo de la situación precaria de quienes se dedicaban a las letras. ${ }^{40}$ Así empieza éste: "Después de largos sufrimientos la poesía hija del cielo acababa de morir; sus sacerdotes nunca han ganado gran cosa y sin duda habrán muerto de hambre” (Simrock 386). En general, a los escritores no se les pagaba lo que se merecían y las críticas de sus pares eran duras y destructivas. El gobierno, por su parte, no los apoyaba económicamente y la misma Universidad de Chile, centro del saber, sólo favorecía a quienes tenían amigos dentro de la institución (Blanco Cuartín 56). En resumidas cuentas, si pocos querían seguir el camino de las letras ("Nuestros propósitos," La esperanza 1) era a causa de que "En nuestra patria ... la carrera de las letras no es carrera, sino senda de sinsabores" ("Editorial” 1-2). Curiosamente, sin embargo, aunque no resultaba rentable escribir en el siglo xix, y aun cuando se buscaba ser lo más europeo posible, con frecuencia se oían voces que clamaban por la existencia de una literatura original que encarnase los verdaderos valores nacionales. Después de todo, al igual que en el caso alemán, la literatura se concebía como un "'medium for a national telos"” (Hohendahl 227). No obstante la naturaleza paradójica del concepto “originalidad”41 que introduce Lastarria en su Discurso de 1842, él es el primero en proponer la creación de una literatura propia: "nuestra literatura debe sernos exclusivamente propia, debe ser enteramente nacional” (10). ${ }^{42}$ Seis años más tarde, Joaquín Blest Gana publica "Causas de la poca orijinalidad de la literatura chilena”. ${ }^{43}$ En 1852, Miguel Luis Amunátegui afirma que la originalidad de la literatura proviene precisamente de la imitación del conocimiento europeo así como de la adaptación del mismo a las circunstancias locales (457-66). Alberto Blest Gana, por su parte, aunque critica el espíritu servil de un pueblo que acriticamente acepta todo lo que viene de Europa, señala en 1861 que en Chile sí existen los elementos para la invención de una literatura nacional ("Literatura chilena” 81-93). ${ }^{44}$ Estos representan algunos de los más significativos dictámenes críticos de la época sobre la originalidad o falta de originalidad de la literatura decimonónica chilena. ${ }^{45}$

Paralelamente al debate sobre la originalidad de la literatura en Chile, se hace sentir la censura de un amplio sector del circuito letrado contra el fuerte apego a las cosas

\footnotetext{
${ }^{40}$ Después de todo, el escritor no podía vivir del aire, tenía que comer (“Prospecto,” El alba 3).

41 "[...] Lastarria en su discurso parece estar planteando, no sabemos si consciente o inconscientemente, una paradoja. Es necesario ser original si lo que se persigue es alcanzar una identidad propia. Sin embargo, dicha originalidad en ningún caso se puede obtener en un vacio cultural privilegiando sólo lo particular. Existen modelos foráneos que bien puede asimilarse,...” (Jocelyn-Holt 77-78).

${ }^{42}$ Pero había quienes pensaban que a una sociedad en transición como la chilena no se le podía exigir originalidad en su literatura ("Literatura nacional” 1-3).

${ }^{43}$ Ese mismo año, en la misma revista, publica "Consideraciones jenerales sobre la poesía chilena" (337-53). Para una visión crítica de la importancia de Joaquín Blest Gana en los albores de la literatura chilena, consúltese el artículo de Rossel.

${ }^{44}$ Algunos años antes, empero, el novelista advertía que no se le podía pedir una "completa originalidad" a "nuestra naciente literatura" ("De los trabajos literarios en Chile" 52).

45 Otros artículos de interés son: "De la literatura chilena. Su nacionalidad”, de D. Demetrio Rodríguez Peña; "Estudio sobre el periodismo y la literatura nacional”, de Manuel Blanco Cuartín; "El alba”, de Sanfurgo; y "El deber de la literatura en nuestra época”, de Juan Enrique Lagarrigue.
} 
materiales de una buena parte de la sociedad chilena. Mientras más se modernizaba la nación, mayores eran sus críticas contra el lujo y el derroche. Algunos castigaban especialmente a la clase pudiente por no vivir una vida más sencilla ("La estrella del sur" 4). Otros pensaban que al prestar demasiada importancia a las modas y el lujo, el pueblo chileno estaba descuidando la ética y la moral ("Verdades amargas” 97). El bienestar material podía llegar a tener consecuencias funestas en la vida de la nación: "Chile se ha muerto de rico, de puro harto" (Lanas 59). Al igual que en otros países del continente, se criticaba fuertemente la influencia negativa que tenía el positivismo particularmente en la cultura: "De las buenas letras ya nadie se ocupa en Chile, como no sean las de cambio. El positivismo lo va abarcando todo, la literatura inclusive” (Perulero 3). ${ }^{46}$ En respuesta a este problema, había quienes juzgaban que los padres debían fomentar "las especiales vocaciones artísticas de sus hijos” y, también, creían que resultaba imprescindible que el país contara con diversiones públicas tales como teatros, bailes públicos, mojigangas, paseos, y otras actividades ("El mosaico. Bellas artes” 1; “Remito” 7-8). Otros juzgaban que solamente a través del impulso de las actividades intelectuales, la fundación de más revistas y, en cierto casos, los esfuerzos del poeta, se podía combatir la creciente fetichización de la vida en Chile (Chacón 2; L. de Guevara 18). Después de todo, el país había gozado de una gran riqueza espiritual e intelectual en la década del cuarenta, década en la que se habían publicado excelentes periódicos literarios y científicos, aun cuando, económicamente, se disponía de mucho menos recursos (Vicuña Mackenna 2).

Resulta lógico, en realidad, que Vicuña Mackenna, letrado tradicional por excelencia, viera con nostalgia la década de la presidencia de Bulnes, década de gran efervescencia cultural en la que los poderosos miembros del circuito letrado tenían en sus manos nada menos que la exclusiva construcción de la nación. Ya para fines del siglo xix, sin embargo, la racionalidad del mercado y la irrupción en la vida político-cultural chilena de sectores populares y medios, iba a transfomar para siempre no solamente la relación escritorEstado sino también la naturaleza misma de aquellos periódicos que tanto echaba de menos Vicuña Mackenna en 1883. Como se ha visto en este artículo, los periódicos literarios jugaron un papel importantísimo en el desarrollo del espíritu nacional. Al igual que los folletines y las novelas nacionales, y de la misma forma que otros mecanismos del Estado tales como la fundación de universidades y la organización de concursos literarios, éstos contribuyeron con creces al establecimiento de una institución literaria que recién en las primeras décadas del siglo xx adquiere una fisonomía sólida. En el proceso de institucionalización de la literatura chilena que se realiza en las revistas literarias en un lapso de cincuenta años, vimos cómo en el seno mismo de un discurso esperanzador y optimista cuyo objetivo no era otro que modernizar y “civilizar” el país, se producía un mensaje paralelo que ponía en tela de juicio toda la empresa ilustrada impulsada con tanto entusiasmo por la clase letrada. Ello tenía que ver, por una parte, con el hecho de que existía un gran trecho entre esta clase y la mayoría de la población chilena; y por otra, con el hecho

\footnotetext{
${ }^{46}$ En su Filosofía de la educación, Valentín Letelier sostiene que desgraciadamente en Chile la fortuna tiene mayor peso que el talento (xvii-viii). Enrique Molina, por su parte, advierte sobre el peligro de una formación exclusivamente práctica (6-14) al mismo tiempo que destaca el marcado materialismo de los chilenos como responsable de la decadencia del nacionalismo (58-59, 81).
} 
de que aun cuando en el transcurso del siglo iban a experimentarse algunas mejorías, eran muy pocos los que tenían acceso a la educación y a los libros. La evolución de la opinión pública en Chile en la segunda mitad del siglo xıx, así como el desarrollo de la clase media y los públicos lectores, fue un proceso menos rápido de lo que pudiera pensarse. Prueba de ello es la tremenda ansiedad que se advierte en los discursos de los patricios modernizadores en las revistas literarias. Por un lado, quieren traer la modernización y el progreso al país, convertir a sus ciudadanos en sujetos “civilizados” y ser útiles a la patria pues son profundamente patrióticos. Pero por otro se quejan de la corta vida de los periódicos literarios y del escaso interés por la lectura y el estudio. Al mismo tiempo, están conscientes de que resulta imposible vivir de la escritura en Chile y piensan que a la literatura chilena le falta originalidad. Lo que ocurre, a fin de cuentas, es que los escritores nacionales (incluyendo a Alberto Blest Gana) no podían dedicarse exclusivamente a la literatura puesto que no existía todavía una burguesía fuerte. No podía exigirse una literatura nacional cuando ni siquiera había una industrial editorial bien desarrollada. En la medida en que la institución literaria fue adquiriendo mayor autonomía y solidez, por supuesto, el discurso nacionalista iba desapareciendo de los periódicos literarios para dar cabida a textos puramente literarios, en el moderno sentido del término.

\section{BiBLIOGRAFÍA}

Achugar, Hugo. "Parnasos fundacionales, letra nación y estado en el siglo xix”. Revista Iberoamericana 178-79 (1997): 13-31.

“A nuestros lectores”. Revista de Sud-América 1 (10/11/1860): 1-6.

“Advertensia.” Revista de artes y letras 1 (15/07/1884): 3-4.

“Al lector.” El mosaico 8 (2/08/1846): 5.

“Algo sobre el teatro.” Revista de Sud-América 2 (25/11/1860): 123-27.

Alonso, Carlos J. The Burden of Modernity. The Rhetoric of Cultural Discourse in Spanish America. New York: Oxford University Press, 1998.

Amunátegui, Miguel Luis. "Discurso de recepción de don Miguel Luis Amunátegui pronunciado en la Facultad de Filosofía i Humanidades de la Universidad de Chile”. Anales de la Universidad de Chile. Santiago: Imprenta chilena, 1852. 457-66.

Arrieta C., Luis, Gustavo A. Holley, Alamiro Huidobro Valdés, Eduardo Lamas G. y Carlos Newman. “A nuestros lectores y colaboradores”. La revista de Chile 1(15/05/ 1898): $1-2$

Barthes, Roland. On Racine. Richard Howard, trad. New York: Hill and Wang, 1964.

Blanco Cuartín, Manuel. "Estudios sobre el periodismo y la literatura nacional”. El mosaico 1 (21/07/1860): 2-9.

Blest Gana, Alberto. “Literatura chilena. Algunas consideraciones sobre ella. -Discurso de don Alberto Blest Gana en su incorporación a la Facultad de Humanidades, leído en la sesión del 3 de enero de 1861”. Anales de la Universidad de Chile. Tomo XVIII. Santiago: Imprenta del Ferrocarril, 1861. 81-93.

“De los trabajos literarios en Chile”. La semana 4 (1859): 51-52.

Blest-Gana, Joaquín. “Causas de la poca orijinalidad de la literatura chilena”. Revista de Santiago 2/1 (1848): 58-72. 
“Consideraciones jenerales sobre la poesía chilena”. Revista de Santiago 2/1 (1848): 337-53.

Bourdieu, Pierre. The Rules of Art. Genesis and Structure of the Literary Field. Susan Emanuel, trad. Stanford: Stanford University Press, 1992.

Brunner, José Joaquín y Gonzalo Catalán. Cinco estudios sobre cultura y sociedad. Santiago: FLACSO, 1985.

Bürger, Peter. Theory of the Avant-Garde. Michael Shaw, trad. Minneapolis: University of Minessota Press, 1984.

Bürger, Peter y Christa Bürger. The Institutions of Art. Lincoln: University of Nebraska Press, 1992.

Burns, E. Bradford. The Poverty of Progress. Latin America in the Nineteenth Century. Berkeley: University of California Press, 1983.

Canepa, Gina. “La poesía popular de pliegos sueltos y folletos del siglo XIX en Chile como periodismo popular”. Anales del Instituto Iberoamericano 2 (1990): 149-68.

“Civilización de las provincias”. El semanario de Santiago 12 (22/09/1842): 99-102.

Chacón, Jacinto. “Nuestros móviles y propósito”. Revista del Pacífico 2/1 (1860): 1-4.

Eagleton, Terry. The Function of Criticism. London: Verso, 1984.

"Editorial”. El eco literario 1 (1888): 1-2.

“El correo”. El correo literario 7 (28/08/1858): 73-74.

“El Mosaico. Bellas artes.” El mosaico 5 (12/07/1846): 1-2.

“El teatro considerado como especulación mercantil”. El mosaico 9 (9/08/1846): 5-7.

F. L. B. “Correspondencia”. El alegre 1/4 (1846): 31-32.

F. M. “Crónicas (interior)”. Revista de Santiago 7/1 (1850): 142-43.

Foresti, Álvaro. "Liberalismo chileno en el siglo xıx. Hacia una unificación de algunos conceptos”. Anales del Instituto Iberoamericano 1 (1989): 21-26.

Foresti, Carlos, Eva Löfquist y Álvaro Foresti. La narrativa chilena desde la Independencia hasta la Guerra del Pacífico (1810-1859). Tomo 1. Santiago: Editorial Andrés Bello, 1999.

La narrativa chilena desde la Independencia hasta la Guerra del Pacífico. Costumbres e historia (1860-1879). Tomo 2. Santiago: Editorial Andrés Bello, 2001.

Foresti, Carlos. "Las letras chilenas 1810-1880. Deslinde para su historia social”. Anales del Instituto Iberoamericano 1 (1989): 11-20.

“Los textos 'literarios' en la prensa chilena (1813-1828). Primeros pasos de la narrativa”. Anales del Instituto Iberoamericano 2 (1990): 5-40.

Galindo, Dunia. "Para una mecánica del cuerpo. Disciplinamiento y subordinación: la sublime teatralidad del nuevo teatro republicano". Revista de crítica literaria latinoamericana 52 (2000): 35-46.

Góngora, Mario. Ensayo histórico sobre la noción de estado en Chile en los siglos XIX y XX. Santiago: Editorial Universitaria, 1986.

González, Marcial. “La emigración europea en sus relaciones con el engrandecimiento de los países de América”. Revista de Santiago 1/1 (1848): 299-322.

González Stephan, Beatriz. La historiografía literaria del liberalismo hispanoamericano del siglo XIX. La Habana: Ediciones Casa de las Américas, 1987. 
"Las disciplinas escriturarias de la patria: constituciones, gramáticas y manuales". Estudios. Revista de investigaciones literarias (Caracas) 5 (1995): 19-46.

Gutiérrez Girardot, Rafael. Modernismo. Barcelona: Montesinos, 1983.

Habermas, Jürgen. The Structural Transformation of the Public Sphere. Thomas Burger, trad. Cambridge: The MIT Press, 1989, 1991.

Hohendahl, Peter Uwe. Building a National Literature. The Case of Germany, 18301870. Trad. Renate Baron Franciscono. Ithaca: Cornell University Press, 1989.

"Influjo del bello sexo sobre la suerte de la humanidad y necesidad de su buena educación”. El semanario de Santiago 31 (2/02/1843).

Jary, David y Julia Jary. Collins Dictionary of Sociology. Glasgow: Harper Collins Publishers, 1995.

J. N. E. “Observaciones sobre la educación de las mujeres dirijidas a las señoras directoras de colejio en Santiago”. El crepúsculo 10 (1/02/1844): 407-19.

Jocelyn-Holt Letelier, Alfredo. "La idea de nación en el pensamiento liberal chileno del siglo XIX”. Opciones. Revista del Centro de Estudios de la realidad contemporánea de la Academia de Humanismo Cristiano 9 (1986): 67-88.

Jusdanis, Gregory. Belated Modernity and Aesthetic Culture. Inventing National Literature. Minneapolis: University of Minnesota P, 1991.

L. J. C. “Reseña sobre el periodismo nacional.” La juventud 1 (1867): 3-4.

L. de Guevara, Salvador. “Reflexiones (A Rafael Egaña)”. El alba 3 (22/05/1871): 17-19.

"La estrella del sur”. La estrella del sur 2 (23/01/1851): 3-5.

Lagarrigue, Juan Enrique. “El deber de la literatura en nuestra época. Discurso pronunciado en la sesión solemne de la Academia de Bellas Letras, celebrada en 27 de mayo de 1877”. Revista chilena. Tomo VIII (1877): 301-09.

Lanas, Juan. “Revista”. El pueblo 4 (18/03/1867): 59-60.

Lastarria, D. J. Victorino. Discurso de Incorporación de D. J. Victorino Lastarria a una sociedad de literatura de Santiago, en la sesión del tres de mayo de 1842. Valparaiso: Imprenta de M. Rivadeneyra, 1842. 1-15.

Letelier, Valentín. Filosofía de la educación. Segunda edición aumentada y correjida. Santiago: Imprenta Cervantes, 1912.

“Literatura nacional.” El mosaico 2 (21/07/1846): 1-3.

Löfquist, Eva. "El proyecto literario nacional y la novelística chilena en sus primeras décadas (1840-1860)”. Anales del Instituto Iberoamericano 2 (1990): 55-80.

Matta, Guillermo. "Revista de Santiago-Santiago, 1 de junio de 1855". Revista de Santiago 1/1 (1855): 45-68.

Molina, Enrique. La cultura y la educación jeneral. Santiago: Imprenta Universitaria, 1912.

“Nuestra primera palabra”. Revista del progreso 1 (1/09/1888): 2-5.

“Nuestras ideas y nuestros propósitos”. Revista americana 1 (8/08/1869): 2-3.

"Nuestros propósitos”. La esperanza 1 (15/set./1871): 1-2.

"Nuestros propósitos”. Revista de Santiago 1/1 (1/05/1872): 1-2.

Orrego de Uribe, Rosario. "Prospecto”. Revista de Valparaíso 1 (1873): 3-4. “La mujer. Poesía leída en la Academia de Bellas Letras”. Revista de Valparaíso 1 (1873): 90-92. 
Orrego Luco, Luis. “A propósito de 'Las pláticas literarias’ de don Pedro N. Cruz, El Naturalismo y la novela contemporánea”. Revista de bellas artes 2 (1889): 33-40.

Ossandón B., Carlos. El crepúsculo de los sabios y la irrupción de los publicistas. Prensa y espacio público en Chile (siglo XIX). Santiago: LOM Ediciones, 1998.

Perkins, David. Is Literary History Possible? Baltimore: The Johns Hopkins University Press, 1992.

Perulero, Antón. "Batturrillo”. La revista cómica 1 (1895): 3-6.

Pinochet, Euridice L. "Aniversario de una academia literaria”. La república 1 (9/09/ 1889): 13.

Pinto, Francisco A. “Consecuencias del indiferentismo literario”. La revista literaria 1/ 1 (1878): 23-25.

Poblete, Juan. "El Castellano: la nueva disciplina y el texto nacional en el fin de siglo chileno”. Revista de crítica cultural 15 (noviembre 1997): 22-27.

"La construcción social de la lectura y la novela nacional: el caso chileno”. Latin American Research Review 2 (noviembre 1997): 75-108.

"Lectura de la sociabilidad y sociabilidad de la lectura: la novela y las costumbres nacionales en el siglo xIX”. Revista de crítica literaria latinoamericana 52 (2000): 11-34.

“Política”. El semanario de Santiago 24 (15/12/1842): 193-95.

Ponce, Manuel Antonio. Enseñanza de la lectura en Chile (Siglos XVI-XIX). Santiago: Imprenta Barcelona, 1905.

“Programa”. El pueblo 1 (25/02/1867): 1.

Promis Ojeda, José. Testimonios y documentos de la literatura chilena. Edición corregida y aumentada. Santiago: Editorial Andrés Bello, 1995.

"Prospecto". El alba 1 (7/05/1871): 2-3.

“Prospecto”. El correo literario 1 (27/08/1867): 1-2.

"Prospecto". El crepúsculo 1/1 (1878): iii-v.

"Prospecto". El museo de ambas Américas 1/1 (1842): 5-10.

“Prospecto”. El semanario de Santiago 1 (14/07/1842): 1-2.

"Prospecto". La estrella del progreso 1 (1/09/1876): 1-2.

"Prospecto”. La linterna 1 (25/08/1867): 1-2.

“Prospecto". Revista de Santiago 1/1 (1848): 6-8.

"Prospecto”. Revista del Pacífico 1/1 (1858): v-vi.

Rama, Ángel. La ciudad letrada. Hanover, NH: Ediciones del Norte, 1984. Rubén Darío y el modernismo. Barcelona: Alfadil Ediciones, 1985.

Ramos, Julio. Desencuentros de la modernidad en América Latina: literatura y política en el siglo XIX. México: Fondo de Cultura Económica, 1989.

Reiss, Timothy J. The Meaning of Literature. Ithaca: Cornell University Press, 1992.

“Remito”. El mosaico 11 (23/08/1846): 7-8.

Rodríguez Peña, D. Demetrio. “De la literatura chilena. Su nacionalidad -su carácter y su influencia en el progreso y felicidad del país. O sea de la literatura chilena, considerada en sus fuentes, y en el carácter que debe revestir para llenar las condiciones de su nacionalidad e influir en el progreso y felicidad del país”. La semana 24 (29/10/1859): 371-77. 
Roig, Arturo Andrés. "El siglo xix latinoamericano y las nuevas formas discursivas”. El pensamiento latinoamericano en el siglo XIX. México: Instituto Panamericano de Geografía e Historia, 1986. 127-40.

Romano, Eduardo. "La oferta literaria inicial de Caras y Caretas". Hispamérica 79 (1998): 19-28.

Rossel, Milton. "Un crítico de nuestro amanecer literario: Joaquín Blest Gana”. Atenea 203 (1942): 202-13.

Salazar V., Gabriel. Labradores, peones y proletarios. Formación y crisis de la sociedad popular chilena del siglo XIX. Santiago: Ediciones Sur, 1985, 1989.

Salazar, Gabriel y Julio Pinto. Historia contemporánea de Chile. Estado, legitimidad, ciudadanía. Vol. I. Santiago: LOM ediciones, 1999.

Sanfurgo. "El alba". El alba 5 (4/06/1871): 33-34

Serrano, Sol. Universidad y nación. Chile en el siglo XIX. Santiago: Editorial Universitaria, 1993.

Silva Castro, Raúl. Antología de poetas chilenos del siglo XIX. Santiago: Imprenta Dirección General de Prisiones, 1937.

Simrock, Karl. “Muerte de la poesía”. El museo 1/24 (1853): 386.

Solar Correa, Eduardo. Escritores de Chile S. XIX. Santiago: Imprenta Universitaria, 1932.

Stuven V., Ana María. La seducción de un orden. Las élites y la construcción de Chile en las polémicas culturales y políticas del siglo XIX. Santiago: Ediciones Universidad Católica de Chile, 2000.

Suárez, José Bernardo. “Bibliografía”. Biblioteca republicana 1/1 (1894): 20-21.

Subercaseaux S. , Bernardo. Cultura y sociedad liberal en el siglo XIX. Santiago: Editorial Aconcagua, 1981.

Fin de siglo. La época de Balmaceda. Santiago: Editorial Aconcagua, 1988.

Historia del libro en Chile (alma y cuerpo). Santiago: Editorial Andrés Bello, 1993.

Toribio Medina, José. Historia de la literatura colonial de Chile. Tomo 1. Santiago: Imprenta de la librería del Mercurio, 1878.

Vera L., Oscar. "Reflexiones sobre la literatura en Chile”. Atenea 100 (1933): 281-93.

“Verdades amargas”. El correo literario 9 (11/09/1858): 97-8.

Vicuña Mackenna, Benjamín. "El ideal de un editor de revistas. (Lo que puede y debe hacerse para dar vida propia y holgada a la literatura nacional)”. La lectura 1/1 (1883): 1-3.

Vilches, Roberto. Las revistas literarias chilenas del siglo XIX. Santiago: Imprenta Universitaria, 1942.

Villalobos R., Sergio, Osvaldo Silva G., Fernando Silva V. y Patricio Estelle M. Historia de Chile. Santiago: Editorial Universitaria, 1974.

Williams, Raymond. Keywords. A Vocabulary of Culture and Society. New York: Oxford University Press, 1976, 1983. Marxism and Literature. Oxford: Oxford University Press, 1977.

Yankas, Lautaro. “De la literatura chilena y la crítica”. Atenea 402 (1964): 111-39. 